\title{
Is forest insurance a relevant vector to induce adaptation efforts to climate change?
}

\author{
Marielle Brunette $^{1} \cdot$ Stéphane Couture $^{2} \cdot$ François Pannequin $^{3}$
}

Received: 15 June 2016 / Accepted: 10 March 2017 / Published online: 11 May 2017

(C) INRA and Springer-Verlag France 2017

\begin{abstract}
- Key message Insurance might be an efficient tool to strengthen adaptation of forest management to climate change. A theoretical model under uncertainty is proposed to highlight the effect, on adaptation decisions, of considering adaptation efforts in forest insurance contracts. Results show that insurance is relevant to increase adaptation efforts under some realistic conditions on forest owner's uncertainty and risk preferences, and on the observability or not of adaptation efforts.

- Context One of the challenges of forest adaptation to climate change is to encourage private forest owners to implement adaptation strategies.

- Aims We suggest the analysis of forest insurance contracts against natural hazards as a vector to promote the implementation of adaptation efforts by private forest owners.

- Methods We propose a theoretical model of insurance economics under risk and under uncertainty.
\end{abstract}

Handling Editor: Rasoul YOUSEFPOUR

This article is part of the Topical Collection on Risk Analysis

Marielle Brunette

marielle.brunette@inra.fr

Stéphane Couture

stephane.couture@inra.fr

François Pannequin

pannequin@ecogest.ens-cachan.fr

1 LEF, AgroParisTech, INRA, 54000 Nancy, France

2 UR 875 Applied Mathematics and Computer Science, INRA, 31326 Castanet-Tolosan, France

3 CES-Cachan and École Normale Supérieure Paris-Saclay, 61 Avenue du Président Wilson, 94230 Cachan, France
- Results Our results indicate that when climate change makes the probability of the occurrence of the natural event uncertain, then it may be relevant to include adaptation efforts in the insurance contract, leading to an increase in the adaptation efforts of risk-averse and uncertainty-averse forest owners. In addition, we show that the relevance of insurance as a vector to promote adaptation efforts is greater when the forest owner's effort is unobservable by the insurer as compared to a situation of perfectly observable effort.

- Conclusion Under some realistic assumptions, the forest insurance contract seems to be a relevant tool to encourage forest owners to adapt to climate change.

Keywords Forest · Insurance · Risk · Uncertainty · Climate change $\cdot$ Adaptation strategy

\section{Introduction}

As a result of increasing temperatures, changes in water regimes and unforeseen disturbances, climate change is likely to have an impact on various ecosystems, especially that of the forest. Indeed, temperature, solar radiation, rainfall and atmospheric $\mathrm{CO}_{2}$ concentrations represent major direct drivers of forest productivity and forest dynamics (Reyer et al. 2014; Scholes et al. 2014). In addition, since forest management decisions have long-term implications because of standard rotation lengths that range from 4 to 15 decades, and because decisions such as the choice of tree density or species are largely irreversible, the forest seems to be of particular interest for analyzing adaptation to climate change.

One of the main concerns with regard to climate change and forests is that climate change increases the frequency and severity of natural events, making forest management riskier (Spittlehouse and Stewart 2003; Van Aalst 2006). In addition, the impact of climate change on the 
characteristics of natural hazards is widely uncertain, particularly in terms of occurrence. An increasing number of natural events have occurred in the last decade, whereas the probability of the occurrence of these events is still largely uncertain. This finding has put governments under increasing pressure to implement policies and investment projects to facilitate climate change adaptation (Hochrainer-Stigler et al. 2014; Van Aalst 2006).

In such a context, many forest adaptation options are recommended to address climate change (Bolte et al. 2009; Yousefpour and Hanewinkel 2015; Keenan 2015). Examples include the reduction of rotation lengths (Spittlehouse and Stewart 2003; Seidl et al. 2011), a shift from monoculture to mixed stands (Shou et al. 2012), planting alternate genotypes or new species (Spittlehouse and Stewart 2003; Carina and Keskitalo 2011), sanitation thinning (Spittlehouse and Stewart 2003; Guariguata et al. 2008), among others. These adaptation strategies represent high costs for the forest owner because they imply extensive modifications of the forest management (Fujimori 2001). In addition, the results of such strategies, although they may reduce risks, are largely unknown in a context of climate change (Bolte et al. 2009).

In addition to these existing adaptation options, the forest owner can also adopt risk-sharing strategies (Riguelle et al. 2016). In some countries (Denmark, France, Germany, Japan, Sweden, etc.), insurance contracts against fire and/or storm are proposed to private forest owners (Holecy and Hanewinkel 2006; Brunette and Couture 2008; Brunette et al. 2015b). The private forest insurance market is different from one country to the next since it depends on environmental, economic and political conditions (Brunette and Couture 2008; Brunette et al. 2015b). For example, in Europe, disparities exist between France and Germany where only 2 and $5 \%$, respectively, of the private forest owners are insured against storm, and Denmark and Sweden where this figure is 68 and 90\%, respectively (Brunette and Couture 2008). Concerning forest fire insurance, Brunette et al. (2015b) reported that only $1.25 \%$ of the insurable land in Spain is insured, and less than $0.5 \%$ of the forest cover in Slovakia. Such insurance also exists outside of Europe, in New Zealand (Manley and Watt 2009), China (Dai et al. 2016), and USA (Deng et al. 2015), for example.

Consequently, in a context where private insurance is available, costly adaptation strategies exist, and the impacts of climate change on the occurrence of natural hazards and the consequences of adaptation actions are largely uncertain, the major question is how to encourage private forest owners to implement adaptation strategies.

In this paper, we suggest the analysis of forest insurance contracts against natural events as a vector to promote the adoption of adaptation strategies by private forest owners. This suggestion is in line with the recommendations to use private-sector insurance as a vehicle to finance climate resilience and adaptation (OECD 2015, Global Agenda Council on Climate Change 2014, Article 4.8 of the United Nations Framework Convention on Climate Change (UNFCCC) and Article 3.14 of the Kyoto Protocol). Our idea is that these existing forest insurance contracts could include the forest owner's adaptation effort. Since adaptation efforts are risk-reducing, they make it possible to decrease the forest insurance premium against natural hazards. Both forest owners and insurers may benefit from such contracts. We propose a theoretical approach to analyze our research question, due to the absence of empirical data about forest owner's observed behaviors in terms of insurance and adaptation efforts.

The standard theoretical framework of insurance demand (Mossin 1968) may be used to model an insurance contract depending on adaptation efforts. This standard framework has rarely been applied to analyze forest insurance. Brunette and Couture (2008) adapted the model of Mossin (1968) to some forest specificities: loss proportional to the value of the forest stand in the event of risk occurrence and a multiple-state model, and studied forest owners' insurance decisions under risk with several public programs. In the same way, Brunette et al. (2013) proposed an extension of the initial Mossin model by considering uncertainty in relation to the probability of risk occurrence, and experimentally tested their theoretical predictions about optimal insurance decisions. They found that participants in the uncertainty context are consistently willing to pay more to be fully insured than participants in the risk situation. To our knowledge, there is no extension of the standard theoretical model that focuses on the introduction of risk-reduction efforts into the insurance contract under uncertainty.

Consequently, we propose a theoretical model of insurance economics that determines the forest owner's optimal adaptation efforts and the associated optimal level of forest insurance. This model will compare different situations. First, we propose to compare the optimal adaptation effort under risk and under uncertainty. Risk refers to a situation where the probability of the occurrence of a disaster is wellknown, whereas uncertainty refers to a situation in which the probability of occurrence is not known (Knight 1921). In our context, a natural event occurrence translates into a financial loss for the forest owners. In theory, all the damaging forest factors, biotic (diseases, pests, and mammals) and abiotic (wind, fire, snow, and drought), generating financial loss may be considered in our model. However, currently, forest insurance contracts exist only for storm and/or fire, which are the more damageable hazards in European forests (Schelhaas et al. 2003). The financial loss, consecutive to the occurrence of the hazard, may gather both timberrelated economic losses (loss of timber marketability, decrease in the future value of the trees that have to be 
harvested at a premature stage, etc) and non-timber-related ones (loss in terms of amenities, carbon sequestration, etc). Under risk, the probability of occurrence of this loss is known, while under uncertainty, we assume that climate change makes the probability of occurrence of the natural hazard uncertain. By doing that, we are consistent with the approach suggested by Yousefpour et al. (2012) who report that: "we are facing a new kind of uncertainties, which has been little addressed in the forest management and decision-making literature and that are those implied by climate change." Second, we consider that the insurer may or may not observe the adaptation effort implemented by the forest owner at the time that the insurance contract is taken out. An observable adaptation effort may be, for example, the financial contribution to a forest adaptation fund. Indeed, some funds related to climate change and the forest have emerged: the Forest Climate Fund in Germany (http://www.bmel.de/EN/Forests-Fisheries/Forests/Texte/ ForestClimateFund.html), the Strategic Forest Carbon Fund in France (http://fbie.org/projet-foret-bois/), etc. They support actions in relation to forest area development, forest resilience, forest adaptation strategies, etc. and, consequently, contribution to such funds may be considered as an observable adaptation effort. In contrast, an unobservable adaptation effort could be the implementation of sanitation thinning or the reduction of rotation length that requires a costly ex ante control by the insurer.

\section{Material and methods}

\subsection{The insurance model under risk}

Consider a private forest owner with an initial wealth $W_{0}$ corresponding to the commercial value of a timber stand at the optimal cut period. This initial wealth is exposed to a probability $q$ that a natural hazard occurrence will affect the value of the forest stand. The proportion of the damaged stand affected by the hazard is designated by $x$. The loss $x W_{0}$ is proportional to the value of the stand, as suggested in the literature (Brunette and Couture 2008). The final wealth would thus be $W_{0}$ if no hazard occurs, or $W_{0}-x W_{0}$ in the case of loss. In order to reduce the risk exposure, the forest owner can make an adaptation effort $a$. Assuming that the forest damage proportion $x$ is a decreasing function of the adaptation effort $a$, we have: $x=x(a), x^{\prime}(a)<0$. Moreover, we assume that the returns on adaptation efforts are decreasing (i.e., $x^{\prime \prime}(a)>0$ ). The forest owner's preferences are characterized by a classical von Neumann-Morgenstern utility function $U(W)$, which is strictly increasing and concave $\left(U^{\prime}(W)>0, U^{\prime \prime}(W)<0\right)$. This risk aversion hypothesis is in line with the forest economics literature that reports that risk aversion plays a significant role in the forest owner's adaptation decision (Brunette et al. 2014a).
In addition, the forest owner may purchase an insurance contract from a risk-neutral insurer that specifies three factors: the insurance premium $P$, the compensation $I$ and the deductible $F$. The unit price of insurance is designated by $p$, so that: $P=p I$.

Consequently, in order to choose the optimal levels of insurance and adaptation effort $\left(F_{R}, a_{R}\right)$, the forest owner maximizes the following expected utility:

$\operatorname{Max}_{\left(F_{R}, a_{R}\right)} E U(W)=(1-q) U\left(W_{1 R}\right)+q U\left(W_{2 R}\right)$

where $W_{1 R}$ is the final wealth with no loss, and $W_{2 R}$ the final wealth when a loss occurs, under risk. In this context, we analyze two situations: when the insurer observes the forest owner's adaptation effort and when the insurer does not observe this effort.

\subsubsection{Observability of the adaptation effort}

When the insurer observes the forest owner's adaptation effort, the compensation is then $I=x\left(a_{R}^{o}\right) W_{0}-F_{R}^{o}$. In such a context, the wealth when no natural hazard occurs is $W_{1 R}^{o}=W_{0}-p\left(x\left(a_{R}^{o}\right) W_{0}-F_{R}^{o}\right)-a_{R}^{o}$ and when it occurs: $W_{2 R}^{o}=W_{0}-p\left(x\left(a_{R}^{o}\right) W_{0}-F_{R}^{o}\right)-a_{R}^{o}-F_{R}^{o}$.

The first-order conditions defining optimal insurance and adaptation effort may be written as follows:

$$
\begin{aligned}
(1-q) U^{\prime}\left(W_{1 R}^{o *}\right)+q U^{\prime}\left(W_{2 R}^{o *}\right)= & q U^{\prime}\left(W_{2 R}^{o *}\right) \times \frac{1}{p} \\
(1-q) U^{\prime}\left(W_{1 R}^{o *}\right)+q U^{\prime}\left(W_{2 R}^{o *}\right)= & -x^{\prime}\left(a_{R}^{o *}\right) W_{0} \\
& \times p\left[(1-q) U^{\prime}\left(W_{1 R}^{o *}\right)\right. \\
& \left.+q U^{\prime}\left(W_{2 R}^{o *}\right)\right]
\end{aligned}
$$

At the optimum, the marginal cost of adaptation effort $a_{R}^{o *}$ (LHS of condition (3)) is equal to its marginal benefit (RHS of condition (3)), in terms of expected utility. The same comment applies for optimal insurance $F_{R}^{o *}$ with regard to condition (2).

\subsubsection{Unobservability of the adaptation effort}

When the insurer does not observe the forest owner's adaptation effort, it is then considered that $a=0$ when calculating the compensation. The compensation is then $I=$ $x(0) W_{0}-F_{R}^{u}$. In such a context, the wealth when no natural hazard occurs is $W_{1 R}^{u}=W_{0}-p\left(x(0) W_{0}-F_{R}^{u}\right)-a_{R}^{u}$ and when it occurs: $W_{2 R}^{u}=W_{0}-p\left(x(0) W_{0}-F_{R}^{u}\right)-a_{R}^{u}-$ $x\left(a_{R}^{u}\right) W_{0}+x(0) W_{0}-F_{R}^{u}$.

After some changes, the first-order conditions defining optimal insurance and unobservable effort may be written as follows:

$$
\begin{aligned}
& (1-q) U^{\prime}\left(W_{1 R}^{u *}\right)+q U^{\prime}\left(W_{2 R}^{u *}\right)=q U^{\prime}\left(W_{2 R}^{u *}\right) \times \frac{1}{p} \\
& (1-q) U^{\prime}\left(W_{1 R}^{u *}\right)+q U^{\prime}\left(W_{2 R}^{u *}\right)=-x^{\prime}\left(a_{R}^{u *}\right) W_{0} q U^{\prime}\left(W_{2 R}^{u *}\right)
\end{aligned}
$$


Then, at the optimum, the marginal cost of optimal insurance $F_{R}^{u *}$ and adaptation effort $a_{R}^{u *}$ (LHS), respectively, is equal to its marginal benefit (RHS) in expected utility terms.

\subsection{The insurance model under uncertainty}

We consider the same forest owner facing the same problem, but since climate change makes the probability of occurrence of natural events uncertain in this case, we assume that the probability $q$ of the loss is uncertain and is represented by a stochastic variable $\tilde{q}=q+\tilde{\varphi}$ with $E(\tilde{\varphi})=0$, where $E$ is the term of expectation for $\tilde{\varphi}$. We consider uncertainty as situations in which forest owners do not have perfect knowledge about the probabilities. In decision theory, such an uncertainty is defined as ambiguity.

The forest owner is characterized by both a von Neumann-Morgenstern utility function $U($.$) , strictly$ increasing and concave $\left(U^{\prime}()>0,. U^{\prime \prime}()<0.\right)$, which captures the owner's risk aversion, and an increasing and concave function $\phi($.) defined over the expectation of $U($.), representing the forest owner's uncertainty aversion. This way to consider uncertainty comes from the expected recursive utility theory of Klibanoff et al. (2005). As usual, we assume that the insurer is risk- and uncertainty-neutral. The forest owner has to choose the insurance deductible $F_{U}$ and the adaptation effort $a_{U}$ under uncertainty.

Thus, in order to choose the optimal couple of decisions $\left(F_{U}, a_{U}\right)$, the forest owner maximizes the following expected recursive utility:

$$
\begin{aligned}
\operatorname{Max}_{\left(F_{U}, a_{U}\right)} E V(W) & =E_{\tilde{\varphi}} \phi[U(W), \tilde{\varphi}] \\
& =E_{\tilde{\varphi}} \phi\left[(1-\tilde{q}) U\left(W_{1 U}\right)+\tilde{q} U\left(W_{2 U}\right)\right]
\end{aligned}
$$

where $W_{1 U}$ is the final wealth with no loss, and $W_{2 U}$ the final wealth when a loss occurs under uncertainty. In this context, we analyze the optimal adaptation effort when the insurer observes and does not observe this effort.

\subsubsection{Observability of adaptation effort}

When the insurer observes the forest owner's adaptation effort, the insurance compensation is then $I=x\left(a_{U}^{o}\right) W_{0}-$ $F_{U}^{o}$. The wealths in both cases are defined as being under risk.

The first-order conditions defining optimal insurance and adaptation effort are respectively:

$$
\begin{aligned}
& E_{\tilde{\varphi}}\left\{\phi^{\prime}[U(W), \tilde{\varphi}]\left[(1-\tilde{q}) U^{\prime}\left(W_{1 U}^{o *}\right) p-\tilde{q} U^{\prime}\left(W_{2 U}^{o *}\right)(1-p)\right]\right\}=0 \\
& E_{\tilde{\varphi}}\left\{\phi^{\prime}[U(W), \tilde{\varphi}]\left[\tilde{q} U^{\prime}\left(W_{2 U}^{o *}\right)\left(-p x^{\prime}\left(a_{U}^{o *}\right) W_{0}-1\right)+(1-\tilde{q}) U^{\prime}\left(W_{1 U}^{o *}\right)\left(-p x^{\prime}\left(a_{U}^{o *}\right) W_{0}-1\right)\right]\right\}=0
\end{aligned}
$$

These conditions reveal that, at the optimum, the marginal cost of insurance and adaptation effort is equal to its marginal benefit, expressed in expected recursive utility terms.

\subsubsection{Unobservability of adaptation effort}

When the insurer does not observe the forest owner's adaptation effort, the compensation is then $I=x(0)-F_{U}^{u}$. The wealths in the two states of the world are defined as being under risk.

In this context, after some rearrangements, the first-order conditions defining optimal insurance and adaptation effort may be written as follows:

$$
\begin{aligned}
\tilde{q} U^{\prime}\left(W_{2 U}^{u *}\right)+(1-\tilde{q}) U^{\prime}\left(W_{1 U}^{u *}\right)= & \frac{\tilde{q} U^{\prime}\left(W_{2 U}^{u *}\right)}{p} \\
& -\frac{\operatorname{cov}\left(\phi^{\prime}[U(W), \tilde{\varphi}], E U_{F}^{\prime}\right)}{E_{\tilde{\varphi}} \phi^{\prime}[U(W), \tilde{\varphi}]} \times \frac{1}{p}
\end{aligned}
$$

$$
\begin{aligned}
\tilde{q} U^{\prime}\left(W_{2 U}^{u *}\right)+(1-\tilde{q}) U^{\prime}\left(W_{1 U}^{u *}\right)= & -\tilde{q} x^{\prime}\left(a_{U}^{u *}\right) W_{0} U^{\prime}\left(W_{2 U}^{u *}\right) \\
& +\frac{\operatorname{cov}\left(\phi^{\prime}[U(W), \tilde{\varphi}], E U_{a}^{\prime}\right)}{E_{\tilde{\varphi}} \phi^{\prime}[U(W), \tilde{\varphi}]}
\end{aligned}
$$

where $E U_{F}^{\prime}=\left[\tilde{q} U^{\prime}\left(W_{2 U}^{u *}\right)(p-1)+(1-\tilde{q}) U^{\prime}\left(W_{1 U}^{u *}\right) p\right]$ and $E U_{a}^{\prime}=\left[\tilde{q} U^{\prime}\left(W_{2 U}^{u *}\right)\left(-1-x^{\prime}\left(a_{U}^{u *}\right) W_{0}\right)-(1-\tilde{q}) U^{\prime}\left(W_{1 U}^{u *}\right)\right]$.
Then, at the optimum, the marginal cost of insurance (LHS of condition (9)) is equal to its marginal benefit (RHS of condition (9)). The same comment applies for the adaptation effort with regard to condition (10).

\section{Results}

\subsection{Observability vs. unobservability}

\subsubsection{Under risk}

When the forest owner's adaptation effort is observable by the insurer, the LHS of conditions (2) and (3) are identical. Then, equalizing the RHS makes it appear that the forest owner invests in adaptation efforts in order to equalize the marginal returns of each risk-reducing mechanism:

$$
-x^{\prime}\left(a_{R}^{o *}\right) W_{0}=\frac{1}{p}
$$

Consequently, at equilibrium, the marginal return of adaptation efforts equalizes the reverse of the marginal return of insurance. The unit price of the insurance then indirectly determines the adaptation effort chosen by the 
forest owner, who sets the level of effort at the point that equalizes marginal returns, and complements it by buying some insurance coverage for the residual risk.

This result is still true when the adaptation effort is unobservable by the insurer. In fact, the LHS of conditions (4) and (5) are identical, so equalizing the RHS leads to the same result as presented in condition (11). This means that under risk, the optimal level of adaptation effort is the same regardless of the observability of the effort.

These findings lead to the following proposition:

Proposition 1 Under risk, the optimal adaptation effort of a risk-averse forest owner is the same when the effort is observable by the insurer as when the effort is unobservable.

The proof of Proposition 1 is given in Appendix A.

Proposition 1 means that under risk, regardless of the observability of the adaptation effort of a risk-averse forest owner by a risk-neutral insurer, the implementation of a forest insurance contract with a premium directly depending on the adaptation effort is ineffective in terms of the individual's incentives to adapt to climate change.

\subsubsection{Under uncertainty}

When the insurer observes the adaptation effort implemented by the forest owner, then equalizing conditions (7) and (8) makes it appear that the equilibrium obtained is the same as that presented in condition (11). Consequently, at equilibrium, the marginal return of the adaptation effort equalizes the reverse of the marginal return of insurance.

However, since we introduce the assumption of unobservability of the adaptation effort, then the equilibrium changes. We can easily observe that the LHS of conditions (9) and (10) are identical. Consequently, equalizing the RHS leads to:

$$
\begin{aligned}
\frac{1}{p}+x^{\prime}\left(a_{U}^{u *}\right) W_{0}= & {\left[\frac{\operatorname{cov}\left(\phi^{\prime}[U(W), \tilde{\varphi}], E U_{a}^{\prime}\right)}{E_{\tilde{\varphi}} \phi^{\prime}[U(W), \tilde{\varphi}]}+\frac{1}{p}\right.} \\
& \left.\times \frac{\operatorname{cov}\left(\phi^{\prime}[U(W), \tilde{\varphi}], E U_{F}^{\prime}\right)}{E_{\tilde{\varphi}} \phi^{\prime}[U(W), \tilde{\varphi}]}\right] \\
& \times \frac{1}{\tilde{q} U^{\prime}\left(W_{2 U}^{u *}\right)}
\end{aligned}
$$

The optimal level of the adaptation effort depends on the comparison between the marginal benefit and the marginal cost of the adaptation effort, as previously presented in condition (11), but also on an additional term whose sign is a function of the uncertainty preferences. Under uncertainty neutrality, the RHS of condition (12) is equal to zero; under uncertainty aversion, it is positive; and under uncertainty prone assumption, this RHS term is negative. This means that under uncertainty neutrality, the optimal adaptation efforts under observability and unobservability are the same, so that implementing an insurance contract with a premium depending on the adaptation effort would not be efficient. Under an uncertainty-prone assumption, the optimal level of the adaptation effort is lower than under uncertainty neutrality. Finally, under uncertainty aversion, the optimal adaptation effort is higher than under neutrality, making the insurance contract relevant to encourage forest owners to adapt to climate change.

These findings lead to the following proposition:

Proposition 2 Under uncertainty, the optimal adaptation effort of a risk-averse and uncertainty-averse forest owner is higher when the effort is unobservable by the insurer than when the effort is observable.

The proof of Proposition 2 is given in Appendix B.

Proposition 2 indicates that under uncertainty, the implementation of a forest insurance contract with a premium depending on the adaptation effort of the owner could be more efficient in terms of an individual's incentives to adapt to climate change when the effort of a risk-averse and uncertainty-averse forest owner is unobservable by the insurer than when it is observable.

\subsection{Risk vs. uncertainty}

The situation under risk does not take the uncertain impact of climate change on the probability of occurrence of natural events into account. Consequently, comparing the optimal adaptation effort under risk (conditions (2), (3), (4), and (5)) and under uncertainty (conditions (7), (8), (9), and (10)) makes it possible to infer the role of climate change in the model. This comparison leads to the following proposition:

Proposition 3 The optimal levels of forest owners' adaptation efforts under risk and under uncertainty when the adaptation effort is observable by the insurer are identical. When the effort is unobservable, the optimal level of adaptation effort under uncertainty is higher (lower or identical, respectively) than the optimal level of adaptation effort under risk if the forest owner is risk-averse and uncertainty-averse (prone or neutral, respectively).

The proof of this proposition is derived from the results obtained in Propositions 1 and 2.

Proposition 3 means that when the uncertain impact of climate change is not taken into account, the insurance contract does not appear to be an interesting vector to promote risk-reducing strategies among the forest owner population. However, the introduction of climate change into the model through its uncertain impact on the probability of the 
occurrence of natural events seems to legitimize the use of forest insurance contracts as incentives to encourage riskaverse and uncertainty-averse forest owners to undertake adaptation efforts to address climate change when the effort is unobservable.

\section{Discussion}

Our results indicate that incorporating adaptation efforts into forest insurance contracts may be an effective mean to encourage forest owners to adapt to climate change when (1) the probability of occurrence of the insured natural event is uncertain, (2) the forest owner is risk-averse and uncertainty-averse, and (3) the forest owner's adaptation effort is unobservable by the insurer. We discuss how realistic these three conditions are below.

Uncertain probabilities The Intergovernmental Panel on Climate Change (IPCC) indicates that "changing climate leads to changes in the frequency, intensity, spatial extent, duration, and timing of extreme weather and climate events, and can result in unprecedented extreme weather and climate events" (IPCC 2012). IPCC (2012) also specifies that, by definition, extreme events seldom occur, so that identifying long-term trends and making projections for the future is therefore very complicated (Banholzer et al. 2014). These findings are in accordance with our point (1). However, they also underline the fact that uncertainty characterizes the intensity of natural events as well, which is probably a promising way to extend our model.

Risk and uncertainty aversion The forest owner's risk aversion is a widespread assumption in the literature. Many theoretical papers have focused on the impact of the forest owner's risk aversion on various types of decisions such as rotation length (Uusivuori 2002; Gong and Löfgren 2003), forest investments (Kangas 1994), harvesting (Brunette et al. 2015a), and species change (Brunette et al. 2014a).

However, few empirical studies have attempted to characterize the forest owner's risk preferences. Lönnstedt and Svensson (2000), through telephone interviews of a sample of Swedish forest owners, found risk-prone attitudes when small sums of money were at stake, whereas they found riskaverse attitudes when large sums were at stake. Andersson and Gong (2010) found that a majority of Swedish forest owners were risk-neutral or risk-prone. As the result of a field experiment they carried out, Brunette et al. (2013) concluded that French private forest owners were risk-averse. Recently, Brunette et al. (2014b) found that French private forest owners are risk-averse with an average relative risk aversion coefficient of 1.15 .
To our knowledge, the only study dealing with the uncertainty aversion of forest owners was proposed by Brunette et al. (2013). They questioned 42 French private forest owners on their willingness-to-pay to be fully insured against forest fire risk. The probability of occurrence of a fire is uncertain. They analyzed the risk and uncertainty preferences through the ratio of willingness-to-pay to expected loss (Kunreuther et al. 1995). The results indicated that this ratio is higher under uncertainty than under risk, regardless of the level of income, concluding that the forest owners interviewed were uncertainty-averse.

This brief overview indicates that our point (2) on risk aversion and uncertainty aversion of private forest owners seems to be plausible.

Unobservable adaptation effort We mentioned many potential adaptation strategies in the introduction: reduction of rotation length, a shift from monoculture to mixed stands, planting alternate genotypes or new species, sanitation thinning, etc. These adaptation strategies are unobservable by the insurer at the time the insurance contract is taken out due to high compliance/control costs. In contrast, financial contribution to a forest adaptation fund is observable by the insurer. Another example may be a financial contribution to firefighting associations like the one existing in the south of France, the DFCI (Defense of Forests against Fire).

It is easy to observe that unobservability by the insurer characterizes most of the adaptation effort that a forest owner may undertake. Cases where the effort is observable by the insurer are scarce and focus mainly on financial contributions, making our point (3) on unobservability realistic.

\section{Conclusion}

This article questions the relevance of incorporating adaptation efforts into forest insurance contracts against natural events as a means to encourage private forest owners to adopt adaptation actions. For that purpose, we propose an insurance economics model that determines the optimal adaptation effort under risk and under uncertainty when the insurer may or may not observe the forest owner's adaptation effort. Uncertainty allows us to consider the impact of climate change on the frequency of natural hazards.

We show that under some assumptions, incorporating the adaptation effort into forest insurance contracts may be a relevant vector to incite the implementation of adaptation strategies by the forest owner. More precisely, such a contract may be useful when the probability of occurrence of the natural hazard is uncertain, the forest owner is riskaverse and uncertainty-averse, and when the forest owner's adaptation effort is unobservable. These assumptions are 
mainly discussed with regard to the literature and were found to be realistic.

Several follow-ups to this paper appear to be of interest. First, as mentioned in the discussion, we assume uncertainty on the probability of occurrence of the natural hazard, but uncertainty may also characterize the damage. Experimental economics studies on this subject have been proposed in an insurance context (Hogarth and Kunreuther 1989; Kunreuther et al. 1993; Jaspersen 2016). Second, it may also be interesting to empirically test the results obtained in this paper through an experiment in which the observability by the insurer of the forest owner's adaptation effort would be taken into consideration.

Acknowledgments This work was supported by the ANR project FORWIND (ANR-12-AGRO-0007). The UMR Économie Forestière is supported by a grant overseen by the French National Research Agency (ANR) as part of the "Investissements d'Avenir" program (ANR-11-LABX-0002-01, Lab of Excellence ARBRE).

\section{Appendix A: Proof of Proposition 1}

Under risk, when the insurer observes the adaptation effort, the first-order conditions are:

$$
\begin{aligned}
\frac{\partial E U(W)}{\partial F}= & p(1-q) U^{\prime}\left(W_{1 R}^{o *}\right)-(1-p) q U^{\prime}\left(W_{2 R}^{o *}\right)=0 \\
\frac{\partial E U(W)}{\partial a}= & {\left[(1-q) U^{\prime}\left(W_{1 R}^{o *}\right)+q U^{\prime}\left(W_{2 R}^{o *}\right)\right] } \\
& \times\left[-p x^{\prime}\left(a_{R}^{o *}\right)-1\right]=0
\end{aligned}
$$

These conditions may be rewritten and lead to conditions (2) and (3). Equalizing these two conditions leads to the result presented in condition (11).
Under risk, when the insurer does not observe the adaptation effort, the first-order conditions are:

$$
\begin{aligned}
\frac{\partial E U(W)}{\partial F} & =p(1-q) U^{\prime}\left(W_{1 R}^{u *}\right)-(1-p) q U^{\prime}\left(W_{2 R}^{u *}\right) \\
& =0 \\
\frac{\partial E U(W)}{\partial a} & =-(1-q) U^{\prime}\left(W_{1 R}^{u *}\right)-\left(1+x^{\prime}\left(a_{R}^{u *}\right)\right) q U^{\prime}\left(W_{2 R}^{u *}\right) \\
& =0
\end{aligned}
$$

These conditions may be rearranged so as to give conditions (4) and (5):

$$
\begin{aligned}
& (1-q) U^{\prime}\left(W_{1 R}^{u *}\right)+q U^{\prime}\left(W_{2 R}^{u *}\right)=q U^{\prime}\left(W_{2 R}^{u *}\right) \times \frac{1}{p} \\
& (1-q) U^{\prime}\left(W_{1 R}^{u *}\right)+q U^{\prime}\left(W_{2 R}^{u *}\right)=-x^{\prime}\left(a_{R}^{u *}\right) W_{0} q U^{\prime}\left(W_{2 R}^{u *}\right)
\end{aligned}
$$

The LHS of these conditions are identical. Therefore, equalizing the RHS leads to the following result:

$-x^{\prime}\left(a_{R}^{u *}\right) W_{0}=\frac{1}{p}$

This condition is the same as condition (11).

\section{Appendix B: Proof of Proposition 2}

Under uncertainty, when the insurer observes the forest owner's adaptation effort, the first-order conditions are given by conditions (7) and (8). Equalizing these two conditions leads to the following result:

$-x^{\prime}\left(a_{U}^{o *}\right) W_{0}=\frac{1}{p}$

Under uncertainty, when the insurer does not observe the adaptation effort, the first-order conditions are:

$$
\begin{aligned}
& \frac{\partial E V(W)}{\partial F}=E_{\tilde{\varphi}}\left\{\phi^{\prime}[U(W), \tilde{\varphi}]\left[\tilde{q} U^{\prime}\left(W_{2 U}^{u *}\right)(p-1)+(1-\tilde{q}) U^{\prime}\left(W_{1 U}^{u *}\right) p\right]\right\}=0 \\
& \frac{\partial E V(W)}{\partial a}=E_{\tilde{\varphi}}\left\{\phi^{\prime}[U(W), \tilde{\varphi}]\left[\tilde{q} U^{\prime}\left(W_{2 U}^{u *}\right)\left(-1-x^{\prime}\left(a_{U}^{u *}\right)\right)-(1-\tilde{q}) U^{\prime}\left(W_{1 U}^{u *}\right)\right]\right\}=0
\end{aligned}
$$

Rearranging these conditions leads to conditions (9) and (10). The LHS of conditions (9) and (10) are identical, and equalizing the RHS leads to the result presented in condition (12). This condition (12) is different from the condition obtained under uncertainty and observability. It depends on the forest owner's uncertainty preferences as follows.

If the individual is uncertainty-neutral $\left(\phi^{\prime \prime}=0\right)$, then the optimal adaptation effort is such that the RHS of condition (12) is equal to zero.

Under uncertainty aversion $\left(\phi^{\prime \prime}<0\right)$, the two covariance terms, $\operatorname{cov}\left(\phi^{\prime}[U(W), \tilde{\varphi}], E U_{a}^{\prime}\right)$ and $\operatorname{cov}\left(\phi^{\prime}[U(W), \tilde{\varphi}]\right.$,
$\left.E U_{F}^{\prime}\right)$, are positive. Indeed, the two terms, $\phi^{\prime}[U(W), \tilde{\varphi}]$ and $E U^{\prime}$, vary in the same way with an increase in the loss $x$. When $x$ increases, the wealth $W$ decreases, the utility decreases and $\phi^{\prime}[U(W), \tilde{\varphi}]$ increases. In the same manner, when $x$ increases, the wealth $W$ decreases, and since $U^{\prime}>0, E U^{\prime}$ increases. Consequently, the RHS of condition (12) is positive and the optimal level of the adaptation effort is higher than under uncertainty neutrality.

If the forest owner is uncertainty-prone $\left(\phi^{\prime \prime}>0\right)$, then the RHS of condition (12) is negative and the optimal level of the adaptation effort is lower than under uncertainty neutrality. 


\section{References}

Andersson M, Gong P (2010) Risk preferences, risk perceptions and timber harvest decisions - an empirical study of nonindustrial private forest owners in Northern Sweden. For Policy Econ 12:330-339

Banholzer S, Kossin J, Donner S (2014) The impact of climate change on natural disasters. Chapter 2. In: Zommers Z, Singh A (eds) Reducing disaster: early warning systems for climate change

Bolte A, Ammer C, Löf M, Madsen P, Nabuurs G-J, Schall P, Spathelf P, Rock J (2009) Adaptive forest management in central Europe: climate change impacts, strategies and integrative concept. Scand J Forest Res 24:473-482

Brunette M, Couture S (2008) Public compensation for windstorm damage reduces incentives for risk management investments. For Policy Econ 10:491-499

Brunette M, Cabantous L, Couture S, Stenger A (2013) The impact of governmental assistance on insurance demand under ambiguity: a theoretical model and an experimental test. Theory Decis 75:153174

Brunette M, Costa S, Lecocq F (2014a) Economics of species change subject to risk of climate change and increasing information: a (quasi-)option value analysis. Ann For Sci 71:279-290

Brunette M, Couture S, Laye J (2015a) Optimizing forest management under storm risk with Markov decision process model. J Environ Econ Policy 4:141-163

Brunette M, Foncel J, Kéré E (2014b) Attitude towards risk and production decision: an empirical analysis on French private forest owners. Études et documents du CERDI $n^{\circ} 10$ avril 2014

Brunette M, Holecy J, Sedliak M, Tucek J, Hanewinkel M (2015b) An actuarial model of forest insurance against multiple natural hazards in fir (Abies Alba Mill.) stands in Slovakia. For Policy Econ 55:46-57

Carina E, Keskitalo H (2011) How can forest management adapt to climate change? Possibilities in different forestry systems. Forests 2:415-430

Dai Y, Chang HH, Liu W (2016) Do forest producers benefit from the forest disaster insurance program? Empirical evidence in Fujian Province of China. For Policy Econ 50:127-133

Deng Y, Munn IA, Coble K, Yao H (2015) Willingness to pay for potential standing timber insurance. J Agri Appl Econ 47:510-538

Fujimori T (2001) Ecological and silvicultural strategies for sustainable forest management. Elsevier Science

Global Agenda Council on Climate Change (2014) Climate adaptation: Seizing the challenge. World Economic Forum Geneva Switzerland. www.weforum.org/reports

Gong P, Löfgren KG (2003) Risk-aversion and the short-run supply of timber. For Sci 49:647-656

Guariguata MR, Cornelius JP, Locatelli B, Forner C, SanchezAzofeifa GA (2008) Mitigation needs adaptation: tropical forestry and climate change. Mitig Adapt Strat Global Change 13:793-808

Hochrainer-Stigler S, Mechler R, Pflug G, Williges K (2014) Funding public adaptation to climate-related disasters estimates for a global fund. Glob Environ Chang 25:87-96

Hogarth RM, Kunreuther H (1989) Risk, ambiguity and insurance. J Risk Uncertainty 2:5-35

Holecy J, Hanewinkel M (2006) A forest management risk insurance model and its application to coniferous stands in Southwest Germany. For Policy Econ 8:161-174

IPCC (2012) In: Field CB, Barros V, Stocker TF, Qin D, Dokken DJ, Ebi KL, Mastrandrea MD, Mach KJ, Plattner G-K, Allen SK, Tignor M, Midgley PM (eds) Managing the risks of extreme events and disasters to advance climate change adaptation. a special report of working groups I and II of the intergovernmental panel on climate change (IPCC). Cambridge University Press, Cambridge, UK/New York, p 582

Jaspersen JG (2016) Hypothetical surveys and experimental studies of insurance demand: a review. J Risk Insur 83:217-255

Kangas J (1994) Incorporating risk attitude into comparison of reforestation alternatives. Scand J For Res 9:297-304

Keenan RJ (2015) Climate change impacts and adaptation in forest management: a review. Ann For Sci 72:145-167

Klibanoff P, Marinacci M, Mukerjji S (2005) A smooth model of decision making under ambiguity. Econometrica 73:1849-1892

Knight F (1921) Risk, uncertainty and profit. Houghton Mifflin, Boston

Kunreuther H, Hogarth RM, Meszaros J (1993) Insurer ambiguity and market failure. J Risk Uncertainty 7:71-87

Kunreuther H, Meszaros J, Hogarth RM, Spranca M (1995) Ambiguity and underwriter decision processes. J Econ Behav Organ 26:337352

Lönnstedt L, Svensson J (2000) Non-industrial private forest owner's risk preferences. Scand J For Res 15:651-660

Manley B, Watt R (2009) Forestry insurance, risk pooling and risk minimisation options. Report prepared for MAF Project CM-09 under MAF POL 0809-11194

Mossin J (1968) Aspects of rational insurance purchasing. J Polit Econ 76:553-568

OECD (2015) Climate change risks and adaptation: linking policy and economic. OECD Publishing, Paris

Reyer C, Lasch-Born P, Suckow F, Gutsch M, Murawski A, Pilz T (2014) Projections of regional changes in forest net primary productivity for different tree species in Europe driven by climate change and carbon dioxide. Ann For Sci 71:211-225

Riguelle S, Hébert J, Jourez B (2016) Integrated and systemic management of storm damage by the forest-based sector and public authorities. Ann For Sci 73:585-600

Schelhaas MJ, Nabuurs GJL, Schuck A (2003) Natural disturbances in the European forests in the 19th and 20th centuries. Glob Chang Biol 9:1620-1633

Scholes R, Settele J, Betts R, Bunn S, Leadley P, Nepstad D, Overpeck J, Angel Taboada M (2014) Terrestrial and inland water systems. In: Climate change 2014: impacts, adaptation and vulnerability. Contribution of working group II to the fifth assessment report of the IPCC. Cambridge University Press, Cambridge

Seidl R, Rammer W, Lexer MJ (2011) Adaptation options to reduce climate change vulnerability of sustainable forest management in the Austrian Alps. Can J Forest Res 41:694-706

Shou E, Jacobsen JB, Kristensen KL (2012) An economic evaluation of strategies for transforming even-aged into near-natural forestry in a conifer-dominated forest in Denmark. For Policy Econ 20:8998

Spittlehouse DL, Stewart RB (2003) Adaptation to climate change in forest management. BC J of Ecosystems Manag 4:1-11

Uusivuori J (2002) Non-constant risk attitudes and timber harvesting. For Sci 48:459-470

Van Aalst MK (2006) The impacts of climate change on the risk of natural disasters. Disasters 30:5-18

Yousefpour R, Jacobsen JB, Thorsen BJ, Meilby H, Hanewinkel M, Oehler K (2012) A review of decision-making approaches to handle uncertainty and risk in adaptive forest management under climate change. Ann For Sci 69:1-15

Yousefpour R, Hanewinkel M (2015) Forestry professionals' perceptions of climate change, impacts and adaptation strategies for forests in South-West Germany. Clim Chang 130:273-286 